\title{
High $b$-Value Diffusion MRI to Differentiate Recurrent Tumors from Posttreatment Changes in Head and Neck Squamous Cell Carcinoma: A Single Center Prospective Study
}

\author{
Angela Acampora, ${ }^{1}$ Gaetana Manzo, ${ }^{2}$ Giacomo Fenza, ${ }^{2}$ Giuseppina Busto, ${ }^{3}$ \\ Antonietta Serino, ${ }^{2}$ and Andrea Manto ${ }^{2}$ \\ ${ }^{1}$ Department of Advanced Biomedical Sciences, Section of Radiology, University of Naples "Federico II", \\ Via Sergio Pansini 5, 80131 Naples, Italy \\ ${ }^{2}$ Department of Neuroradiology, Umberto I Hospital, Viale San Francesco 2, 84014 Nocera Inferiore, Italy \\ ${ }^{3}$ Department of Onco-Hematology, DEA Nocera-Pagani, Umberto I Hospital, Viale San Francesco 2, 84014 Nocera Inferiore, Italy
}

Correspondence should be addressed to Andrea Manto; and.manto@libero.it

Received 8 March 2016; Revised 30 April 2016; Accepted 12 May 2016

Academic Editor: Sotirios Bisdas

\begin{abstract}
Copyright (c) 2016 Angela Acampora et al. This is an open access article distributed under the Creative Commons Attribution License, which permits unrestricted use, distribution, and reproduction in any medium, provided the original work is properly cited.

Recently DW-MR Imaging has shown promising results in distinguishing between recurrent tumors and posttreatment changes in Head and Neck Squamous Cell Carcinoma (HNSSC). Aim of this study was to evaluate the diagnostic performances of DWI at high $b$-value $\left(b=2000 \mathrm{~s} / \mathrm{mm}^{2}\right)$ compared to standard $b$-value $\left(b=1000 \mathrm{~s} / \mathrm{mm}^{2}\right)$ and $\mathrm{ADC}_{\text {ratio }}$ values $\left(\mathrm{ADC}_{\text {ratio }}=\mathrm{ADC}_{2000} / \mathrm{ADC}_{1000} \times 100\right)$ to differentiate recurrent tumors from posttreatment changes after treatment of HSNCC. 20 patients (16 M, 4 F) underwent MR Imaging between 2 and 16 months (mean 7) after treatment. Besides morphological sequences, we performed single-shot echo-

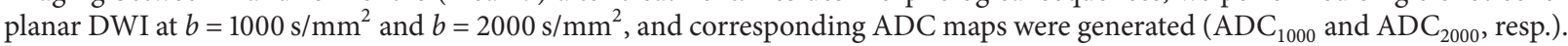
By considering contrast-enhanced T1-weighted images as references, ROIs were drawn in order to evaluate mean $\mathrm{ADC}_{1000}, \mathrm{ADC}_{2000}$, and $\mathrm{ADC}_{\text {ratio }}$. The mean $\mathrm{ADC}_{1000}$ and $\mathrm{ADC}_{2000}$ in recurrent tumors were significantly lower than those in posttreatment changes ( $P=0.001$ and $P=0.016$, resp.). Moreover, the mean $\mathrm{ADC}_{\text {ratio }}$ between the two groups showed a statistically significant difference $(P=0.002)$. Sensitivity, specificity, and accuracy of $\mathrm{ADC}_{\text {ratio }}$ were $82.0 \%, 100 \%$, and $90 \%$, respectively, by considering an optimal cutoff value of $65.5 \%$. $\mathrm{ADC}_{\text {ratio }}$ is a promising value to differentiate between recurrent tumors and posttreatment changes in HNSCC and may be more useful than $\mathrm{ADC}_{1000}$ and $\mathrm{ADC}_{2000}$.
\end{abstract}

\section{Introduction}

Squamous cell carcinoma represents almost $90 \%$ of the head and neck tumors (HNSCC) and it shows different biological behaviors according to location [1].

Imaging techniques are commonly required in order to define tumor's locoregional extension [2]. Moreover MRI is increasingly becoming the preferred examination method as it provides additional information on tumor extension, muscles and lymph nodes involvement, and skull base and intracranial invasion. The role of MRI can therefore modify the clinical staging and consequently therapeutical approach, which is multidisciplinary with surgery, radiation therapy, and/or chemotherapy.
In these patients, however, even if treatment improves survival and quality of life, on the other hand, it can delay detection of residual or recurrent tumor in posttreatment follow-ups as surgery can modify anatomy and radiochemotherapy can result in edema, inflammation, fibrosis, and, sometimes, necrosis [3-5].

Conventional MR Imaging gives sometimes wrong information as postcontrast enhancement of a benign lesion may mimic a residual or a recurrent tumor, leading to an increased number of false positives and unnecessary surgical approaches. On the contrary, a recurrent tumor may not show enhancement after the administration of contrast medium.

Recently, DW (diffusion-weighted) MR Imaging has shown promising results. DWI is based on the Brownian 
motion of water protons, which is affected by the microstructure of tissue. Several promising studies have been reported on the usefulness of DWI in the discrimination between recurrent or residual tumor and posttreatment changes [68].

In recent years, high $b$-value $\left(b>1000 \mathrm{~s} / \mathrm{mm}^{2}\right)$ DWI was introduced along with improvements in MR Imaging gradient technology compared with standard $b$-value $(b=$ $1000 \mathrm{~s} / \mathrm{mm}^{2}$ ) DWI [9-11].

The aim of our present study was to evaluate the diagnostic performance of high $b$-value $\left(b=2000 \mathrm{~s} / \mathrm{mm}^{2}\right) \mathrm{DW}$ sequences compared with standard $b$-value $\left(b=1000 \mathrm{~s} / \mathrm{mm}^{2}\right)$ DWI, and the ratio of ADC values from high and standard $b$-values for the differentiation between recurrent tumor and posttreatment changes after treatment (chemoradiotherapy and/or surgery) of HSNCC.

\section{Materials and Methods}

2.1. Population. A prospective study has been conducted between January 2013 and April 2014 by analysing 20 consecutive patients (16 M, 4 F, age range $41-81$ years, mean age 60 ) with a previous (pathologically confirmed) diagnosis of Head and Neck Squamous-Cellular tumor (Table 1). All patients have been analysed in their follow-up after surgery and/or chemoradiotherapy after a strong suspicion of residual or recurrent tumor because of the recurrence of symptoms (Pt. numbers $5,6,7,12,13,16,19$, and 20) or because of clinical suspicion at follow-up (e.g., palpable mass) (Pt. numbers 1, 2, $3,4,8,9,10,11,14,15,17$, and 18). Primary tumor locations were nasopharynx $(n=10)$, tongue $(n=3)$, parotid gland $(n=3)$, oropharynx $(n=2)$, larynx $(n=1)$, and cheek $(n=1)$. All patients with nasopharynx tumors (Pt. numbers $1,2,3,4,5,9,11,13,17$, and 18) were treated with 3 cycles of docetaxel, cisplatin, and 5-fluorouracil (TPF schedule) as induction chemotherapy followed by a subsequent concomitant chemoradiation.

As regarding patients with tongue cancer, one patient (Pt. number 20) was treated with surgery and then chemotherapy (cisplatin) and another one (Pt. number 6) with concomitant chemoradiotherapy while the third one underwent both a conservative surgical approach and right laterocervical lymph nodes dissection (II-III levels) followed by concomitant chemoradiation.

Patients affected by oropharynx cancer (Pt. numbers 12 and 15) were treated with chemotherapy and radiotherapy.

Those with ductal epidermoid cancer of the parotid gland (Pt. numbers 10, 14, and 19) were treated with parotidectomy followed by chemotherapy and radiotherapy.

The patient with a transglottic laryngeal cancer (Pt. number 7) was treated with chemotherapy and concomitant radiation therapy.

The one with a spinocellular cancer of the right cheek (Pt. number 8) had the resection of the lesion followed by locoregional radiotherapy.

Radiotherapy was performed with a linear multileaf accelerator and radiation field dimensions were decided by taking into account tumor extension, staging, and risk of lymph nodes involvement.
2.2. MR Imaging. All patients underwent head/neck area MR Imaging between 2 and 16 months (mean 7) after treatment by using a $1.5 \mathrm{~T}$ MR Imaging system (Philips Intera) with a surface head and neck synergy coil.

The study protocol included

(i) SE T1w axial (TR: 1300-2000 ms; TE: 15 ms; NSA: 2; section thickness: $4 \mathrm{~mm}$; FOV: $220 \times 220 \mathrm{~mm}$; matrix: $224 \times 157)$;

(ii) TSE T2w axial (TR: 9900-14800 ms; TE: $120 \mathrm{~ms}$; NSA: 2; section thickness: $4 \mathrm{~mm}$; FOV: $220 \times 220 \mathrm{~mm}$; matrix: $224 \times 157)$;

(iii) STIR axial and coronal (TR: $1600 \mathrm{~ms}$; TE: $23 \mathrm{~ms}$; NSA: 2; section thickness: $4 \mathrm{~mm}$; FOV: $220 \times 220 \mathrm{~mm}$; matrix: $336 \times 235$ );

(iv) SE T1w axial and coronal with fat suppression (TR: 800-3100 ms; TE: $15 \mathrm{~ms}$; NSA: 2; section thickness: $4 \mathrm{~mm}$; FOV: $220 \times 220 \mathrm{~mm}$; matrix: $368 \times 256$ );

(v) SE T1w with fat suppression (TR: $800-3300 \mathrm{~ms}$; TE: $15 \mathrm{~ms}$; NSA: 2; section thickness: $4 \mathrm{~mm}$; FOV: 220 $\times 220 \mathrm{~mm}$; matrix: $368 \times 258$ ) after intravenous injection of $0.1 \mathrm{mmol} / \mathrm{kg}$ of gadoterate meglumine (Dotarem; Guerbet, Milan, Italy) in transverse, coronal, and sagittal planes.

EPI single-shot DWI sequences were obtained in the transverse plane before contrast agent injection both at standard $b$-values $\left(b=0\right.$ and $b=1000 \mathrm{~s} / \mathrm{mm}^{2}$; TR: $8000 \mathrm{~ms}$; TE: $89 \mathrm{~ms}$; NSA: 1; section thickness: $4 \mathrm{~mm}$; bandwidth: $1913 \mathrm{~Hz} /$ pixel; FOV: $240 \times 240 \mathrm{~mm}$; matrix: $112 \times 89)$ and high $b$-values $(b=0$ and $b=2000 \mathrm{~s} / \mathrm{mm}^{2}$; TR: $9325 \mathrm{~ms}$; TE: $107 \mathrm{~ms}$; NSA: 4; section thickness: $4 \mathrm{~mm}$; bandwidth: $1833 \mathrm{~Hz} /$ pixel; FOV: $240 \times$ 240 mm; matrix: $112 \times 89$ ).

DWI data were acquired in 3 orthogonal directions $(X, Y$, and $Z$ ) and combined into a trace image. The average duration of DWI at standard $b$-value $\left(b=0\right.$ and $\left.b=1000 \mathrm{~s} / \mathrm{mm}^{2}\right)$ was $58 \mathrm{sec}$ while at high $b$-values $\left(b=0\right.$ and $\left.b=2000 \mathrm{~s} / \mathrm{mm}^{2}\right)$ was $2 \mathrm{~min}$ and $20 \mathrm{sec}$.

The corresponding ADC maps were automatically derived from the following equation: $\mathrm{ADC}=\ln [S(b) / S(0)] / b$, where $b$ is the diffusion weighting factor $(b=1000$ or $2000 \mathrm{~s} / \mathrm{mm}^{2}$ ), and $S(b)$ and $S(0)$ are the signal intensities with and without diffusion-sensitizing gradients, respectively.

2.3. Image Analysis. MR images were reviewed on a PACS workstation monitor (Carestream Health).

$\mathrm{ADC}_{\text {ratio }}$ maps $\left(\mathrm{ADC}_{\text {ratio }}=\mathrm{ADC}_{2000} / \mathrm{ADC}_{1000} \times 100\right.$, where $\mathrm{ADC}_{1000}$ and $\mathrm{ADC}_{2000}$ are the $\mathrm{ADC}$ values of $\mathrm{DWI}$ obtained with $b=0$ and $1000 \mathrm{~s} / \mathrm{mm}^{2}$, and $b=0$ and $2000 \mathrm{~s} / \mathrm{mm}^{2}$, resp.) were generated by a specific software by use of pixel-by-pixel computation of ADC maps.

For each patient, two radiologists analysed both conventional MRI and diffusion-weighted (DW) sequences at the same time and recurrence versus posttreatment changes diagnosis was obtained by radiologists' concordance.

MRI examination was followed by biopsy in all patients in order to confirm the diagnosis.

Eight patients underwent surgical biopsy (Pt. numbers 5, $6,7,12,13,16,19$, and 20), 8 core biopsy (Pt. numbers 1,2 , 
TABLE 1: Diagnosis and staging, therapy, and interval between treatment and imaging of 20 patients affected by Head and Neck Squamous Cell Carcinoma (HNSCC).

\begin{tabular}{|c|c|c|c|c|}
\hline Patient & Age/sex & Diagnosis & Therapy & After treatment imaging (months) \\
\hline 1 & $64 / \mathrm{M}$ & Ca nasopharynx $\mathrm{T}_{4 \mathrm{a}} \mathrm{N}_{1} \mathrm{M}_{0}$ & CTRT & 13 \\
\hline 2 & $54 / \mathrm{F}$ & Ca nasopharynx $\mathrm{T}_{4 \mathrm{a}} \mathrm{N}_{2 \mathrm{~b}} \mathrm{M}_{0}$ & CTRT & 6 \\
\hline 3 & $69 / \mathrm{M}$ & Ca nasopharynx $\mathrm{T}_{3} \mathrm{~N}_{1} \mathrm{M}_{0}$ & CTRT & 8 \\
\hline 4 & $50 / \mathrm{M}$ & Ca nasopharynx $\mathrm{T}_{3} \mathrm{~N}_{1} \mathrm{M}_{0}$ & CTRT & 7 \\
\hline 5 & $51 / \mathrm{M}$ & Ca nasopharynx $\mathrm{T}_{4 \mathrm{a}} \mathrm{N}_{1} \mathrm{M}_{0}$ & CTRT & 10 \\
\hline 6 & $68 / \mathrm{M}$ & Ca tongue $\mathrm{T}_{4 \mathrm{a}} \mathrm{N}_{2 \mathrm{~b}} \mathrm{M}_{0}$ & CTRT & 5 \\
\hline 7 & $66 / \mathrm{M}$ & Ca larynx $\mathrm{T}_{4 \mathrm{a}} \mathrm{N}_{2 \mathrm{a}} \mathrm{M}_{0}$ & CTRT & 9 \\
\hline 8 & $79 / \mathrm{M}$ & Ca cheek $\mathrm{T}_{3} \mathrm{~N}_{0} \mathrm{M}_{0}$ & Surgery + RT & 10 \\
\hline 9 & $50 / \mathrm{M}$ & Ca nasopharynx $\mathrm{T}_{3} \mathrm{~N}_{1} \mathrm{M}_{0}$ & CTRT & 3 \\
\hline 10 & $50 / \mathrm{M}$ & Ca parotid gland $\mathrm{T}_{2} \mathrm{~N}_{2 \mathrm{a}} \mathrm{M}_{0}$ & Surgery + CTRT & 10 \\
\hline 11 & $46 / \mathrm{M}$ & Ca nasopharynx $\mathrm{T}_{4 \mathrm{a}} \mathrm{N}_{2 \mathrm{~b}} \mathrm{M}_{0}$ & CTRT & 8 \\
\hline 12 & $68 / \mathrm{M}$ & Ca oropharynx $\mathrm{T}_{2} \mathrm{~N}_{1} \mathrm{M}_{0}$ & CTRT & 5 \\
\hline 13 & $55 / \mathrm{M}$ & Ca nasopharynx $\mathrm{T}_{4 \mathrm{~b}} \mathrm{~N}_{2 \mathrm{c}} \mathrm{M}_{0}$ & CTRT & 4 \\
\hline 14 & $65 / \mathrm{F}$ & Ca parotid gland $\mathrm{T}_{2} \mathrm{~N}_{2 \mathrm{a}} \mathrm{M}_{0}$ & Surgery + CTRT & 16 \\
\hline 15 & $48 / \mathrm{M}$ & Ca oropharynx $\mathrm{T}_{2} \mathrm{~N}_{1} \mathrm{M}_{0}$ & CTRT & 2 \\
\hline 16 & $81 / \mathrm{M}$ & Ca tongue $\mathrm{T}_{4 \mathrm{a}} \mathrm{N}_{2 \mathrm{~b}} \mathrm{M}_{0}$ & Surgery + CTRT & 4 \\
\hline 17 & $77 / \mathrm{F}$ & Ca nasopharynx $\mathrm{T}_{3} \mathrm{~N}_{1} \mathrm{M}_{0}$ & CTRT & 6 \\
\hline 18 & $41 / \mathrm{M}$ & Ca nasopharynx $\mathrm{T}_{4 \mathrm{~b}} \mathrm{~N}_{2 \mathrm{c}} \mathrm{M}_{0}$ & CTRT & 8 \\
\hline 19 & $53 / \mathrm{M}$ & Ca parotid gland $\mathrm{T}_{2} \mathrm{~N}_{2 \mathrm{~b}} \mathrm{M}_{0}$ & Surgery + CTRT & 5 \\
\hline 20 & $74 / \mathrm{F}$ & Ca tongue $\mathrm{T}_{1} \mathrm{~N}_{0} \mathrm{M}_{0}$ & Surgery + CT & 9 \\
\hline
\end{tabular}

$3,4,9,11,15$, and 17), and 4 FNAB (Pt. numbers $8,10,14$, and 19). Biopsy was performed $10-20$ days after MRI examination (average time 15 days).

An expert pathologist confident with head and neck tumors analysed every sample.

2.3.1. Qualitative Analysis: Conventional MRI and DW Sequences. The analysis included tumor site alterations such as high signal intensity on $\mathrm{T} 2 \mathrm{w}$ and STIR sequences, tissue volume increase (focal or diffuse), mass effect, and enhancement pattern after contrast medium injection.

The increasing volume of focal areas of enhancement, at subsequent controls, was considered highly suspicious of tumor recurrence while volume reduction of the lesion or loss of growth at follow-ups was considered as posttreatment changes.

Regarding DW sequences, high signal intensity on high $b$ value images but low signal intensity on corresponding ADC maps were considered suggestive of recurrent tumor whereas high signal intensity on high- $b$-value images but generally high signal intensity on the corresponding ADC maps were considered as a result of $\mathrm{T} 2$ shine-through effect and therefore predictive of posttreatment changes.

2.3.2. Quantitative Analysis: DW Sequences. In order to analyse ADC values in suspected areas, radiologists placed ROIs (regions of interest) on the axial $\mathrm{ADC}_{1000}$ maps with references of contrast-enhanced T1-weighted images obtained in 3 orthogonal planes. ROIs were drawn on the most representative section of the ADC map, in which the size of the tumor was the largest or the conspicuity of the lesion was the highest.
ROI was drawn as large as the visible tumor was on that section of the ADC map corresponding to the contrastenhanced T1-weighted images, trying to avoid necrotic portions and normal osseous structures.

Subsequently, ROIs were copied onto the corresponding $\mathrm{ADC}_{2000}$ and $\mathrm{ADC}_{\text {ratio }}$ maps, respectively.

The size of each ROI was also recorded, varying according to tumor extension (average size $189 \pm 65 \mathrm{~mm}^{2}$ ).

2.4. Statistical Analysis. Statistical analysis was performed with SPSS Statistics 19.0 for Windows. For all statistical analyses, a 2-tailed $P$ value of 0.05 was considered to indicate a statistically significant difference. The 2-tailed independent Student's $t$-test was used to compare mean $\mathrm{ADC}_{1000}$, $\mathrm{ADC}_{2000}$, and $\mathrm{ADC}_{\text {ratio }}$ values between the group with recurrent tumor and the group with post-treatment changes.

Student's $t$-test was also performed in order to compare mean $\mathrm{ADC}_{2000}$ values decreasing percentages versus $\mathrm{ADC}_{1000}$ ones between recurrent tumor group and posttreatment changes one.

A ROC (receiver operating characteristic) curve was drawn to investigate the optimal cutoff values for $\mathrm{ADC}_{1000}$, $\mathrm{ADC}_{2000}$, and $\mathrm{ADC}_{\text {ratio }}$ in order to obtain the best sensitivity, specificity, and accuracy in distinguishing between recurrent tumor and posttreatment changes.

\section{Results}

In our study, 11 patients were found to have a recurrent tumor and 9 posttreatment changes. 


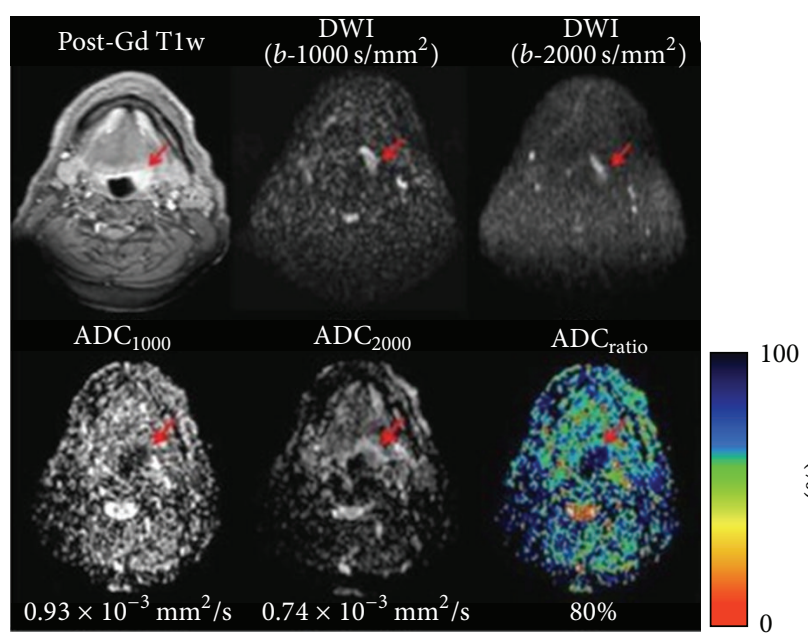

(a)

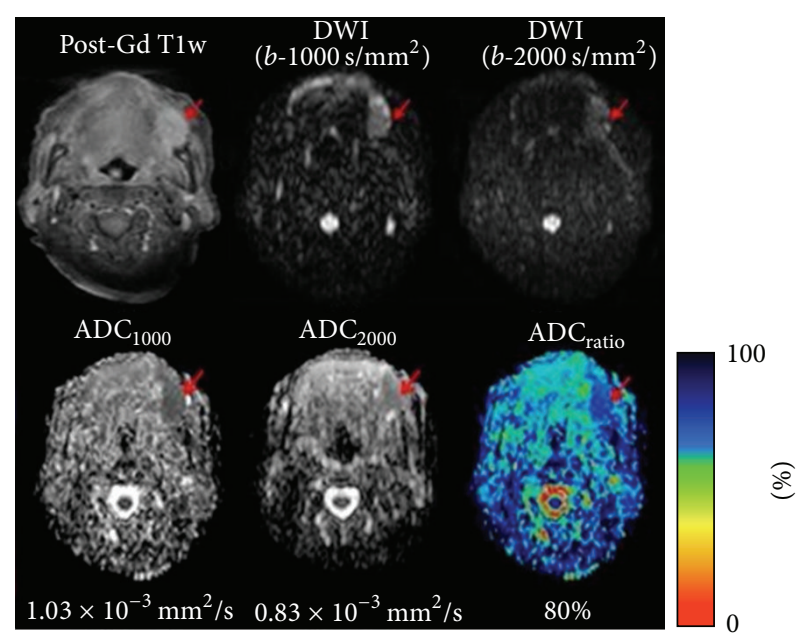

(b)

Figure 1: Representative MR images of recurrent tumors. (a) Patient number 12 (M, 68 yo) treated with chemoradiotherapy for a squamous cell carcinoma of the oropharynx. Postcontrast T1-weighted sequence shows an enhanced thickening of the left wall of oropharynx. (b) Patient number 20 (F, 74 yo) after surgery and radiotherapy for a squamous cell carcinoma of the tongue. Postcontrast T1-weighted sequence demonstrates an enhanced exophytic lesion of the left margin of the tongue. Recurrent tumors are characterized by high signal intensity on $\mathrm{DWI}$ at standard and high $b$-values and low signal intensity on the corresponding $\mathrm{ADC}$ maps. Mean $\mathrm{ADC}_{1000}, \mathrm{ADC}_{2000}$, and $\mathrm{ADC}$ ratio $\mathrm{were}$ $0.93 \times 10^{-3} \mathrm{~mm}^{2} / \mathrm{s}, 0.74 \times 10^{-3} \mathrm{~mm}^{2} / \mathrm{s}$, and $80 \%$ (a) and $1.03 \times 10^{-3} \mathrm{~mm}^{2} / \mathrm{s}, 0.83 \times 10^{-3} \mathrm{~mm}^{2} / \mathrm{s}$, and $80 \%$ (b).

Conventional MRI sequences showed different degrees of anatomic changes after therapy, with a tissue asymmetric increased thickness as the most common. Suspected areas volume increase, together with a high signal intensity on $\mathrm{T} 2 \mathrm{w}$ and STIR images and enhancement after contrast injection were found in 10 patients out of 11 with pathologically confirmed tumor and in 5 patients out of 9 with posttreatment changes (sensitivity $90 \%$, specificity $44 \%$, and accuracy $70 \%$ ).

Recurrent tumors appeared as high signal intensity areas on DWI sequences and low signal ones in the corresponding ADC maps (Figure 1), except for one lesion that had a high signal intensity in the ADC maps; in fact this area showed a relatively high $\mathrm{ADC}_{1000}$ value $\left(1.50 \times 10^{-3} \mathrm{~mm}^{2} / \mathrm{s}\right)$ and intermediate $\mathrm{ADC}_{2000}$ and $\mathrm{ADC}_{\text {ratio }}$ values $\left(0.85 \times 10^{-3} \mathrm{~mm}^{2} / \mathrm{s}\right.$ and $56 \%$, resp.) and it was considered as a posttreatment change (Pt. number 19).

Posttreatment changes showed high or low signal intensity on DWI sequences and high signal intensity on the corresponding ADC maps (Figure 2), except for two, which showed low/mixed signal intensity. Furthermore, their $\mathrm{ADC}_{1000}$ values were relatively low $\left(1.40 \times 10^{-3} \mathrm{~mm}^{2} / \mathrm{s}\right.$ and $1.48 \times 10^{-3} \mathrm{~mm}^{2} / \mathrm{s}$ resp. $)$ while $\mathrm{ADC}_{2000}\left(0.86 \times 10^{-3} \mathrm{~mm}^{2} / \mathrm{s}\right.$ and $0.93 \times 10^{-3} \mathrm{~mm}^{2} / \mathrm{s}$, resp.) and $\mathrm{ADC}_{\text {ratio }}(61 \%$ and $63 \%$, resp.) values were high and they were classified as recurrent tumors (Pt. numbers 1 and 14).

With information given by DWI sequences, MRI accuracy was $85 \%$, with sensitivity and specificity of $90 \%$ and $78 \%$, respectively.

In our study the smallest lesion found to be a recurrent tumor had a maximum diameter of $8 \mathrm{~mm}$.
3.1. Comparison of $A D C_{1000}, A D C_{2000}$, and $A D C_{\text {ratio }}$ between Patients with Recurrent Tumor and Patients with Posttreatment Changes. 11 patients with residual/recurrent tumor had $\mathrm{ADC}_{1000}$ values between $0.93 \times 10^{-3} \mathrm{~mm}^{2} / \mathrm{s}$ and $1.50 \times$ $10^{-3} \mathrm{~mm}^{2} / \mathrm{s}$ with mean $\mathrm{ADC}_{1000}$ of $1.27 \pm 0.22 \times 10^{-3} \mathrm{~mm}^{2} / \mathrm{s}$.

Nine patients with posttreatment changes had $\mathrm{ADC}_{1000}$ values between $1.40 \times 10^{-3} \mathrm{~mm}^{2} / \mathrm{s}$ and $2.53 \times 10^{-3} \mathrm{~mm}^{2} / \mathrm{s}$ with mean $\mathrm{ADC}_{1000}$ of $1.90 \pm 0.44 \times 10^{-3} \mathrm{~mm}^{2} / \mathrm{s}$.

The mean $\mathrm{ADC}_{1000}$ between the two groups showed a statistically significant difference $(P=0.001)$.

$\mathrm{ADC}_{2000}$ values of recurrent tumor group ranged from $0.72 \times 10^{-3} \mathrm{~mm}^{2} / \mathrm{s}$ to $1.05 \times 10^{-3} \mathrm{~mm}^{2} / \mathrm{s}$ with a mean of $0.87 \pm 0.13 \times 10^{-3} \mathrm{~mm}^{2} / \mathrm{s}$ while the ones in the group with posttreatment changes varied between $0.79 \times 10^{-3} \mathrm{~mm}^{2} / \mathrm{s}$ and $1.44 \times 10^{-3} \mathrm{~mm}^{2} / \mathrm{s}$ with a mean of $1.08 \pm 0.21 \times 10^{-3} \mathrm{~mm}^{2} / \mathrm{s}$. The difference between the mean $\mathrm{ADC}_{2000}$ of the two groups was statistically significant $(P=0.016)$.

$\mathrm{ADC}_{\text {ratio }}$ values varied from $54 \%$ to $80 \%$ with a mean value of $69.5 \pm 9.3 \%$ in the recurrent tumor group, while they varied from $46 \%$ to $65 \%$ with a mean value of $56.8 \pm 6.3 \%$ in the posttreatment changes group.

The difference between the mean $\mathrm{ADC}_{\text {ratio }}$ of the recurrent tumor group and that of the posttreatment changes one was statistically significant $(P=0.002)$ (Tables 2 and 3$)$.

$\mathrm{ADC}_{2000}$ values were significantly lower than $\mathrm{ADC}_{1000}$ ones $(P<0.001)$ with a decreasing percentage of $31 \pm 9.7 \%$ in the recurrent tumor group and $42.6 \pm 6.5 \%$ in the posttreatment changes group (Table 4).

A statistically significant difference was also found in the decreasing percentage of the mean $\mathrm{ADC}_{2000}$ versus $\mathrm{ADC}_{1000}$ 


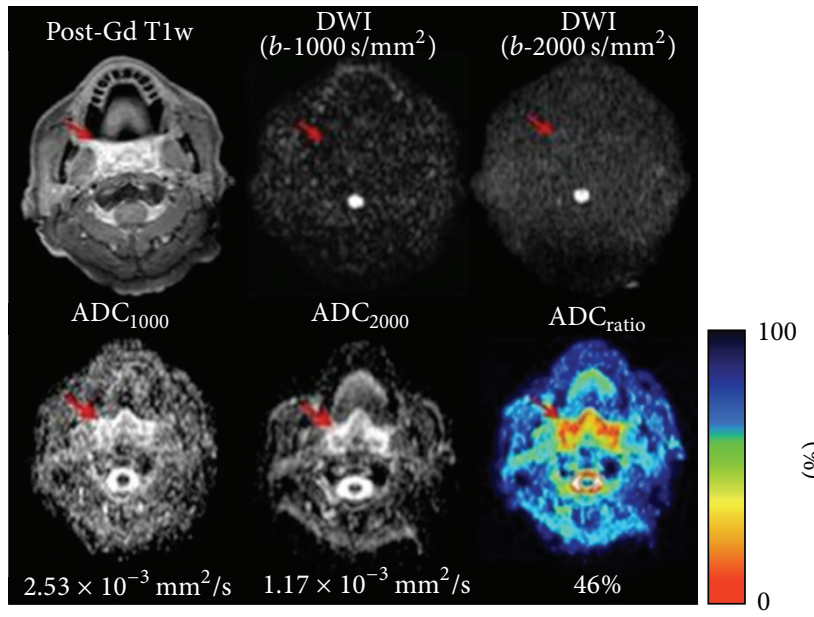

(a)

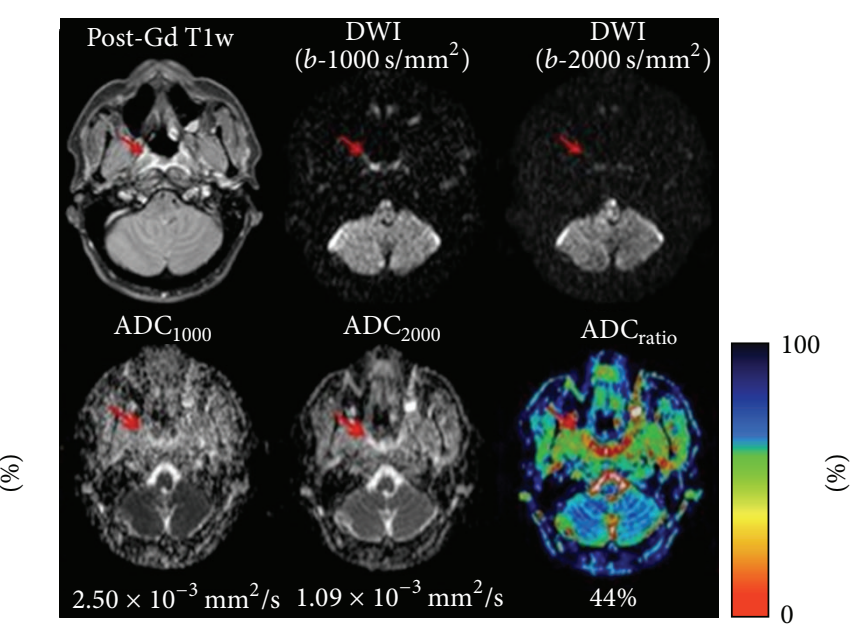

(b)

Figure 2: Representative MR images of posttreatment changes: (a) patient number 3 (M, 69 yo) after radiation therapy for an oropharynx cancer. Postcontrast T1-weighted sequence shows a diffuse and enhanced oropharyngeal thickening. Signal intensity is not increased on DW images at standard and high $b$-values. (b) Patient number 9 (M, 50 yo) after chemoradiotherapy for a nasopharyngeal cancer. Postcontrast T1-weighted sequence shows a right posterolateral thickening of nasopharynx. DW images at standard and high $b$-values depicted a mild high signal intensity (T2 shine-through effect). In both cases, posttreatment changes are characterized by high signal intensity on the corresponding $\mathrm{ADC}$ maps. Mean $\mathrm{ADC}_{1000}, \mathrm{ADC}_{2000}$, and $\mathrm{ADC}_{\text {ratio }}$ were $2.53 \times 10^{-3} \mathrm{~mm}^{2} / \mathrm{s}, 1.17 \times 10^{-3} \mathrm{~mm}^{2} / \mathrm{s}$, and $46 \%(\mathrm{a})$ and $2.50 \times 10^{-3} \mathrm{~mm}^{2} / \mathrm{s}, 1.09 \times$ $10^{-3} \mathrm{~mm}^{2} / \mathrm{s}$, and $44 \%(\mathrm{~b})$.

TABLE 2: $\mathrm{ADC}_{1000}, \mathrm{ADC}_{2000}$, and $\mathrm{ADC}_{\text {ratio }}$ range of values.

\begin{tabular}{lccc}
\hline & Range $\mathrm{ADC}_{1000}$ & ${\text { Range } \mathrm{ADC}_{2000}}$ & Range ADC $_{\text {ratio }}$ \\
\hline Tumor recurrence & $(0.93-1.50) \times 10^{-3} \mathrm{~mm}^{2} / \mathrm{s}$ & $(0.72-1.05) \times 10^{-3} \mathrm{~mm}^{2} / \mathrm{s}$ & $54-80 \%$ \\
Posttreatment changes & $(1.40-2.53) \times 10^{-3} \mathrm{~mm}^{2} / \mathrm{s}$ & $(0.79-1.44) \times 10^{-3} \mathrm{~mm}^{2} / \mathrm{s}$ & $46-65 \%$ \\
\hline
\end{tabular}

TABLE 3: ADC mean values of suspected areas.

\begin{tabular}{lccc}
\hline & $\begin{array}{c}\text { Value }(\text { mean } \pm \mathrm{SD}) \\
\text { Recurrent tumor }\end{array}$ & $\begin{array}{c}\text { Value (mean } \pm \mathrm{SD}) \\
\text { Posttreatment changes }\end{array}$ & $P$ value \\
\hline $\mathrm{ADC}_{1000}\left(\times 10^{-3} \mathrm{~mm}^{2} / \mathrm{s}\right)$ & $1.27 \pm 0.22$ & $1.90 \pm 0.44$ & 0.001 \\
$\mathrm{ADC}_{2000}\left(\times 10^{-3} \mathrm{~mm}^{2} / \mathrm{s}\right)$ & $0.87 \pm 0.13$ & $1.08 \pm 0.21$ & 0.016 \\
$\mathrm{ADC}_{\text {ratio }}(\%)$ & $69.5 \pm 9.3$ & $56.8 \pm 6.3$ & 0.002 \\
\hline
\end{tabular}

TABLE 4: $\mathrm{ADC}_{1000}$ and $\mathrm{ADC}_{2000}$ mean values and decreasing percentage.

\begin{tabular}{lcccc}
\hline & $\mathrm{ADC}_{1000}$ & $\mathrm{ADC}_{2000}$ & $P$ value & Decreasing percentage \\
\hline Recurrent tumor & $1.27 \pm 0.22$ & $0.87 \pm 0.13$ & $<0.001$ & $31 \pm 9.7 \%$ \\
Posttreatment changes & $1.90 \pm 0.44$ & $1.08 \pm 0.21$ & $<0.001$ & $42.6 \pm 6.5 \%$ \\
\hline
\end{tabular}

between recurrent tumor group and posttreatment changes ( $31 \pm 9.7 \%$ versus $42.6 \pm 6.5 \% ; P=0.007)$.

\subsection{Optimal Cutoff Values and Diagnostic Performances. By} considering an optimal cutoff value of $1.53 \times 10^{-3} \mathrm{~mm}^{2} / \mathrm{s}$ for the $\mathrm{ADC}_{1000}$ in order to distinguish between recurrent tumor and posttreatment changes, we obtained the higher accuracy of $90 \%(18 / 20)$, while sensitivity, specificity, PPV, and NPV were $100 \%$ (11/11), 78\% (7/9), 85\%, and $100 \%$, respectively.

By considering an optimal cutoff value of $0.99 \times$ $10^{-3} \mathrm{~mm}^{2} / \mathrm{s}$ for $\mathrm{ADC}_{2000}$ accuracy was $75 \%$ (15/20), while sensitivity, specificity, PPV, and NPV were $82 \%$ (9/11), 67\% (6/9), $75 \%$, and $75 \%$, respectively.

For $\mathrm{ADC}_{\text {ratio }}$, the optimal cutoff value was $65.5 \%$, and the accuracy was $90 \%(18 / 20)$, while sensitivity, specificity, PPV, and NPV were 82\% (9/11), 100\% (9/9), 100\%, and 82\%, respectively (Table 5).

\section{Discussion}

DW imaging is a functional MR Imaging technique that enables depiction and quantification of the Brownian motion 
TABLE 5: Diagnostic performances and cutoff values of $\mathrm{ADC}_{1000}, \mathrm{ADC}_{2000}$, and $\mathrm{ADC}_{\text {ratio }}$.

\begin{tabular}{lcccccc}
\hline & Cutoff value & Sensitivity & Specificity & PPV & NPV & Accuracy \\
\hline $\mathrm{ADC}_{1000}$ & $1.53 \times 10^{-3} \mathrm{~mm}^{2} / \mathrm{s}$ & $100 \%$ & $78 \%$ & $85 \%$ & $100 \%$ & $90 \%$ \\
$\mathrm{ADC}_{2000}$ & $0.99 \times 10^{-3} \mathrm{~mm}^{2} / \mathrm{s}$ & $82 \%$ & $67 \%$ & $75 \%$ & $75 \%$ & $75 \%$ \\
$\mathrm{ADC}_{\text {ratio }}$ & $65.5 \%$ & $82 \%$ & $100 \%$ & $100 \%$ & $82 \%$ & $90 \%$ \\
\hline
\end{tabular}

TABLE 6: $\mathrm{ADC}_{1000}$ cutoff value and diagnostic performances compared to previous studies.

\begin{tabular}{|c|c|c|c|c|}
\hline & $\mathrm{ADC}_{1000}$ cutoff value & Sensitivity & Specificity & Accuracy \\
\hline Abdel Razek et al. [7] -32 Pt. & $1.30 \times 10^{-3} \mathrm{~mm}^{2} / \mathrm{s}$ & $85 \%$ & $90 \%$ & $87 \%$ \\
\hline Vandecaveye et al. [8]-26 Pt. & $1.30 \times 10^{-3} \mathrm{~mm}^{2} / \mathrm{s}$ & $95 \%$ & $95 \%$ & $95 \%$ \\
\hline King et al. [6]-20 Pt. & $1.40 \times 10^{-3} \mathrm{~mm}^{2} / \mathrm{s}$ & $80 \%$ & $100 \%$ & $90 \%$ \\
\hline Hwang et al. [11] —33 Pt. & $1.46 \times 10^{-3} \mathrm{~mm}^{2} / \mathrm{s}$ & $85 \%$ & $85 \%$ & $85 \%$ \\
\hline Present study-20 Pt. & $1.53 \times 10^{-3} \mathrm{~mm}^{2} / \mathrm{s}$ & $100 \%$ & $78 \%$ & $90 \%$ \\
\hline
\end{tabular}

of water molecules in vivo [12-14] therefore reflecting the variability of cellular tissue structure. The ability to investigate intracellular environment has led us to believe that DWI and the corresponding ADC values (apparent diffusion coefficient) can easily distinguish between neoplastic tissues and necrotic nonneoplastic ones. In 2001 Baur et al. analysed the role of diffusion-weighted imaging to differentiate tumor recurrences from posttherapeutical soft-tissue changes in musculoskeletal tumors, by qualitatively evaluating regions of interest's loss of signal on DW imaging; they found that the loss of signal was significantly higher for hygromas and muscles edematous changes compared to recurrent tumors [15]. Not many years later, Hein et al. demonstrated a statistically significant difference between ADC values of recurrent highgrade gliomas and posttreatment changes [16].

According to these encouraging results, several studies have been conducted to assess the role of DW sequences in distinguishing between recurrent tumor and posttreatment changes in head and neck squamous cell tumors. In 2010 King et al. showed how DW imaging enables detection of early pathologic changes after chemoradiotherapy in 50 patients with HNSCC and particularly found that $\mathrm{ADC}_{1000}$ value measured in a suspected area at follow-up is an important marker of recurrent tumor. Moreover, with a cutoff value of $1.40 \times 10^{-3} \mathrm{~mm}^{2} / \mathrm{s}$, the accuracy was $95 \%$ [6].

In a retrospective study on 33 patients (Hwang et al., 2013) with high suspicion of recurrent tumor after chemoradiotherapy and/or surgery, with DW imaging at standard $b$-values ( 0 and $1000 \mathrm{~s} / \mathrm{mm}^{2}$ ) and high $b$-values (0 and $\left.2000 \mathrm{~s} / \mathrm{mm}^{2}\right)$, the comparison of $\mathrm{ADC}_{1000}, \mathrm{ADC}_{2000}$, and $\mathrm{ADC}_{\text {ratio }}$ values between the two groups of patients (recurrent lesions versus posttreatment changes) depicted a statistically significant difference only for $\mathrm{ADC}_{1000}$ and $\mathrm{ADC}_{\text {ratio }}$ mean values in the two groups. By choosing a cutoff value of $1.46 \times$ $10^{-3} \mathrm{~mm}^{2} / \mathrm{s}$ for $\mathrm{ADC}_{1000}$ and of $62.6 \%$ for $\mathrm{ADC}_{\text {ratio }}$ the diagnostic accuracy was $85 \%$ and $84.8 \%$, respectively [11].

Our results demonstrate that ADC values derived from standard $b$-value DWI (1000 $\left.\mathrm{s} / \mathrm{mm}^{2}\right)$ had a similar diagnostic performance compared with previous studies and that the mean $\mathrm{ADC}_{1000}$ in the posttreatment changes group was significantly higher than the one of the recurrent tumor group $\left(1.90 \pm 0.44 \times 10^{-3} \mathrm{~mm}^{2} / \mathrm{s}\right.$ versus $1.27 \pm 0.22 \times 10^{-3} \mathrm{~mm}^{2} / \mathrm{s}$, resp.; $P=0.001)$.

The optimal cutoff value for the $\mathrm{ADC}_{1000}(1.53 \times$ $10^{-3} \mathrm{~mm}^{2} / \mathrm{s}$ ) to distinguish between recurrent tumor and posttreatment changes and the diagnostic accuracy (90\%) is also related to previous studies (Table 6). These findings support the use of standard $b$-value DWI on posttreatment follow-up imaging of HNSCC as the mean values of the $\mathrm{ADC}_{1000}$ in the recurrent tumor group are significantly lower than those of the group with posttreatment changes.

According to Hwang et al.s study, we observed a significant difference in the mean $\mathrm{ADC}_{\text {ratio }}$ between the recurrent tumor group and the posttreatment changes one $(69.5 \pm 9.3 \%$ versus $56.8 \pm 6.3 \%$, resp.; $P=0.002$ ); with a cutoff value of $65.5 \%$ the diagnostic accuracy was $90 \%$ (Table 7 ).

Furthermore, contrary to Hwang et al.s study, we also observed a statistically significant difference in the $\mathrm{ADC}_{2000}$ mean values between the two groups $\left(0.87 \pm 0.13 \times 10^{-3} \mathrm{~mm}^{2} / \mathrm{s}\right.$ versus $1.08 \pm 0.21 \times 10^{-3} \mathrm{~mm}^{2} / \mathrm{s}$, resp.; $\left.P=0.016\right)$. With an $\mathrm{ADC}_{2000}$ cutoff value of $0.99 \times 10^{-3} \mathrm{~mm}^{2} / \mathrm{s}$, the accuracy was 75\% (Table 8).

The two groups ADC values reflect the differences in histopathology and in water molecules distribution between tumors and posttreatment changes. Indeed, ADC is inversely related to tumor cellularity as the increase in cells number and in nucleus dimensions in malignant lesions leads to limitation of diffusion of water molecules and, consequently, to lower ADC values.

On the other hand, decreased cellularity and the presence of edema and inflammatory changes in posttreatment modification are related to higher ADC values.

According to our results, ADC values have also a substantial decrease by increasing the $b$-value over $1000 \mathrm{~s} / \mathrm{mm}^{2}$.

DeLano et al. subjected 50 patients to brain diffusionweighted imaging with $b$-values of $0,1000,2000,2500,3000$, and $3500 \mathrm{~s} / \mathrm{mm}^{2}$. For 6 patients, apparent diffusion coefficient maps were generated at $b$-values of 0 and at $b$-values of 1000 , 2000 , and $3000 \mathrm{~s} / \mathrm{mm}^{2}$. Quantitative assessments were made in multiple regions of interest in gray and white matter and, for some ROI, the ADC decreased approximately of $30 \%$ to $35 \%$ for $b$-values between 1000 and $3000 \mathrm{~s} / \mathrm{mm}^{2}$. These data 
TABLE 7: Comparison of $\mathrm{ADC}_{\text {ratio }}$ cutoff value and diagnostic performances between the present study and Hwang et al's study [11].

\begin{tabular}{|c|c|c|c|c|}
\hline & $\mathrm{ADC}_{\text {ratio }}$ cutoff value & Sensitivity & Specificity & Accuracy \\
\hline Hwang et al. [11] $-33 \mathrm{Pt}$. & $62.6 \%$ & $95 \%$ & $69.2 \%$ & $84.8 \%$ \\
\hline Present study-20 Pt. & $65.5 \%$ & $82 \%$ & $100 \%$ & $90 \%$ \\
\hline
\end{tabular}

TABLE 8: Comparison of $\mathrm{ADC}_{2000}$ cutoff value and diagnostic performances between the present study and Hwang et al's study [11].

\begin{tabular}{lcccc}
\hline & $\mathrm{ADC}_{2000}$ cutoff value & Sensitivity & Specificity & Accuracy \\
\hline Hwang et al. [11]-33 Pt. & - & - & - & - \\
Present study -20 Pt. & $0.99 \times 10^{-3} \mathrm{~mm}^{2} / \mathrm{s}$ & $82 \%$ & $67 \%$ & $75 \%$ \\
\hline
\end{tabular}

indicate that if the relationship between MR signal and $b$ values would have been monoexponential, the ADC value should remain constant as the $b$-value increases. A likely explanation is that apparent diffusion is more accurately represented by a biexponential relation [17].

Both in animal and human models, rapidly decaying and slowly decaying diffusion components have been described. At low $b$-values, signal intensity is dominated by a fast diffusion component, $D_{\text {fast }}$, whereas, at higher $b$-values, signal intensity is contributed largely by the slower component of diffusion, $D_{\text {slow. }}$. Intracellular and extracellular water are considered to correspond to slow and fast diffusion components, respectively, even if not exactly equal to them.

The increasing of intracellular water due to hypercellularity of a recurrent tumor and the reduction of the extracellular space can thus explain the more significant influence of the slow diffusion component on DWI sequences; on the contrary, posttreatment changes edema is related to the predominance of the extracellular water and, consequently, of the fast diffusion component [18].

In our study $\mathrm{ADC}_{1000}$ and $\mathrm{ADC}_{2000}$ maps were obtained from DWI sequences at two $b$-values $\left(0\right.$ and $1000 \mathrm{~s} / \mathrm{mm}^{2} ; 0$ and $2000 \mathrm{~s} / \mathrm{mm}^{2}$, resp.) with a total scan time of $3 \mathrm{~min}$ and $20 \mathrm{sec}$.

We hypothesized that, by increasing the $b$-value from $1000 \mathrm{~s} / \mathrm{mm}^{2}$ to $2000 \mathrm{~s} / \mathrm{mm}^{2}$, the decrease in ADC value would reflect the proportion between slow and fast diffusion components in suspected areas.

The analysis of the two groups (recurrent tumor and posttreatment changes) showed a lower decreasing percentage of the mean $\mathrm{ADC}_{2000}$ compared to the mean $\mathrm{ADC}_{1000}$ in recurrent tumor group $(31 \pm 9.7 \%$ versus $42.6 \pm 6.5 \%$; $P=$ $0.007)$ and a higher $\mathrm{ADC}_{\text {ratio }}(69.5 \pm 9.3 \%$ versus $56.8 \pm 6.3 \%$; $P=0.002)$. We suggest that the lower decrease of ADC values of recurrent lesions by increasing the $b$-value from 1000 to $2000 \mathrm{~s} / \mathrm{mm}^{2}$ can be easily explained by the higher cellularity thus reflecting the greater influence of the slow diffusion component. Furthermore, in tumors, the greater the proportion of slow diffusion component becomes, the higher the $\mathrm{ADC}_{\text {ratio }}$ increases, and, for this reason, the latter might become an alternative biomarker for higher cellularity and it might also simplify the detection of recurrent tumor by visual inspection in the $\mathrm{ADC}_{\text {ratio }}$ maps.

Our results are in agreement with those of earlier studies.
In the present study, qualitative and quantitative analysis of DWI sequences and the corresponding ADC maps revealed one false negative and two false positives.

Signal intensity on diffusion-weighted images is influenced by two factors: water diffusibility and the intrinsic $\mathrm{T} 2$ properties of the tissue being examined. In tissues with very long $\mathrm{T} 2$ relaxation times, the strong $\mathrm{T} 2$ signal may be mistaken for restricted diffusion, a phenomenon known as "T2 shine-through effect." The easiest way to distinguish between restricted diffusion and T2 shine-through is to generate an ADC map, on which the former appears as an area of low signal intensity (low ADC values) and the latter as a high-signal-intensity area [19].

Therefore, high signal intensity on high- $b$-value images and low signal intensity on corresponding ADC maps were considered suggestive of recurrent tumor whereas high signal intensity on high- $b$-value images and generally high signal intensity on the corresponding ADC maps were considered as a result of T2 shine-through effect and therefore predictive of posttreatment changes.

The relatively high ADC values of the recurrent tumor wrongly classified as posttreatment changes may be correlated with the presence of edema and small areas of postradiation colliquative necrosis as well reported by Matzek et al. in a previous study on oropharynx squamous cell carcinoma [20]. As concerns the two false positives, they underwent radiotherapy in the previous year. Nomayr et al. reported that the first visible effect in the first 6 months after irradiation is edema together with fibroinflammatory reaction and increasing permeability due to damage of vessels endothelium. Later on (6-24 months after irradiation) there is the regression of inflammatory edema and the increasing in fibrous reaction, which shows a restricted diffusion [4].

The choice of regions of interest (ROIs) places an important role in order to reduce pitfalls in the evaluation of mean ADC values. Firstly, ROIs should be drawn manually and no necrosis areas should be included; secondly, the more heterogeneous the lesion, the more the ROIs that should be considered from which a mean value should be extrapolated.

However, partial volume artifacts and areas of micronecrosis cannot be avoided during measurement of $\mathrm{ADC}$ values therefore still representing a sampling source of errors [21]. The overlapping of ADC values could be associated with partial volume artifacts due to structures 
sizes, wrongly low $\mathrm{ADC}$ values can be obtained with fibrosis, while wrongly high ADC values can be depicted in necrotic areas of recurrent tumors.

DWI single-shot echoplanar sequence (EPI) was performed for qualitative and quantitative analysis. It has a time resolution of less than $200 \mathrm{~ms}$, thus guaranteeing data acquisition at different $b$-values in a relatively short total scan time. However its weakness is its extreme sensitivity to susceptibility artifacts consequently producing more geometrical distortion artifacts with the increase of $b$-values.

The head and neck region is particularly difficult for performing DW imaging acquisitions because it is very heterogeneous, containing a variety of tissues that include fat, muscle, air, glandular tissue, and bone. It also has very low acquirable signal (from muscle and suppressed fat) and a strongly changing geometric shape. This can yield images with a very low signal-to-noise ratio and strong susceptibility artifacts from many air tissue boundaries, as well as from metallic surgical implants and dental fillings. Moreover, head and neck area is subject to a number of movement-related problems [22-24].

One limitation of our study concerns patients' enrollment as the HNSCC population was quite heterogeneous (various locations and pathologic condition, different treatment modalities, and timing of imaging) and this heterogeneity has made the homogenization of our results difficult.

In our opinion, however, lesion location should not have a significant impact on ADC values whereas the standardization of imaging timing, which could theoretically have an influence on results, is difficult to apply.

Future studies on a less heterogeneous population are required to better analyze the role of these variables on ADC values.

\section{Conclusions}

The present prospective study on HNSCC patients treated with surgery and/or chemoradiotherapy has shown high accuracy of DW-MR Imaging in distinguishing between recurrent tumor and posttreatment changes. We also suggest that ADC measurement both at standard and high $b$-values is required to assess slow diffusion component, which is directly proportional to intracellular water. We suggest that the $\mathrm{ADC}_{\text {ratio }}$ calculated from $\mathrm{ADC}_{1000}$ and $\mathrm{ADC}_{2000}$ is a promising value to differentiate between recurrent tumor and posttreatment changes in HNSCC and may be more useful than $\mathrm{ADC}_{1000}$ and $\mathrm{ADC}_{2000}$ alone.

High $b$-value DWI of head and neck region is technically feasible and requires a relatively short additional scan time but should always be analysed by taking into account morphological sequences in order to correctly localize lesions. However, larger studies are required for the standardization of this imaging to improve single patient application.

\section{Competing Interests}

The authors declare that they have no competing interests.

\section{References}

[1] B. A. C. Van Dijk, G. Gatta, R. Capocaccia, D. Pierannunzio, P. Strojan, and L. Licitra, "Rare cancers of the head and neck area in Europe," European Journal of Cancer, vol. 48, no. 6, pp. 783796, 2012.

[2] Associazione Italiana di Oncologia Medica (AIOM), Milano: Associazione Italiana di Oncologia Medica Guidelines for Head and Neck Tumors, 2015, http://www.aiom.it/professionisti/documenti\%2Dscientifici/linee\%2Dguida/1,413,1,\#TopList.

[3] P. Zbären, M. Caversaccio, H. C. Thoeny, M. Nuyens, J. Curschmann, and E. Stauffer, "Radionecrosis or tumor recurrence after radiation of laryngeal and hypopharyngeal carcinomas," Otolaryngology_Head and Neck Surgery, vol. 135, no. 6, pp. 838-843, 2006.

[4] A. Nömayr, M. Lell, R. Sweeney, W. Bautz, and P. Lukas, "MRI appearance of radiation-induced changes of normal cervical tissues," European Radiology, vol. 11, no. 9, pp. 1807-1817, 2001.

[5] C. Offiah and E. Hall, "Post-treatment imaging appearances in head and neck cancer patients," Clinical Radiology, vol. 66, no. 1, pp. 13-24, 2011.

[6] A. D. King, F. K. F. Mo, K.-H. Yu et al., "Squamous cell carcinoma of the head and neck: diffusion-weighted MR imaging for prediction and monitoring of treatment response," European Radiology, vol. 20, no. 9, pp. 2213-2220, 2010.

[7] A. A. K. Abdel Razek, A. Y. Kandeel, N. Soliman et al., "Role of diffusion-weighted Echo-Planar MR imaging in differentiation of residual or recurrent head and neck tumors and posttreatment changes," American Journal of Neuroradiology, vol. 28, no. 6, pp. 1146-1152, 2007.

[8] V. Vandecaveye, F. De Keyzer, S. Nuyts et al., "Detection of head and neck squamous cell carcinoma with diffusion weighted MRI after (chemo)radiotherapy: correlation between radiologic and histopathologic findings," International Journal of Radiation Oncology Biology Physics, vol. 67, no. 4, pp. 960-971, 2007.

[9] H. S. Seo, K.-H. Chang, D. G. Na, B. J. Kwon, and D. H. Lee, "High b-value diffusion ( $b=3000 \mathrm{~s} / \mathrm{mm} 2)$ MR imaging in cerebral gliomas at 3T: visual and quantitative comparisons with $\mathrm{b}=$ 1000 s/mm 2," American Journal of Neuroradiology, vol. 29, no. 3, pp. 458-463, 2008.

[10] T. J. Yun, J.-H. Kim, K. H. Kim, C.-H. Sohn, and S.-W. Park, "Head and neck squamous cell carcinoma: differentiation of histologic grade with standard- and high-b-value diffusionweighted MRI," Head and Neck, vol. 35, no. 5, pp. 626-631, 2013.

[11] I. Hwang, S. H. Choi, Y.-J. Kim et al., "Differentiation of recurrent tumor and posttreatment changes in head and neck squamous cell carcinoma: application of high b-value diffusionweighted imaging," American Journal of Neuroradiology, vol. 34, no. 12, pp. 2343-2348, 2013.

[12] J. B. Vermorken, E. Remenar, C. van Herpen et al., "Cisplatin, fluorouracil, and docetaxel in unresectable head and neck cancer," The New England Journal of Medicine, vol. 357, no. 17, pp. 1695-1704, 2007.

[13] R. Hermans, "Posttreatment imaging in head and neck cancer," European Journal of Radiology, vol. 66, no. 3, pp. 501-511, 2008.

[14] P. Zbären, S. Weidner, and H. C. Thoeny, "Laryngeal and hypopharyngeal carcinomas after (chemo)radiotherapy: a diagnostic dilemma," Current Opinion in Otolaryngology and Head and Neck Surgery, vol. 16, no. 2, pp. 147-153, 2008.

[15] A. Baur, A. Huber, S. Arbogast et al., "Diffusion-weighted imaging of tumor recurrencies and posttherapeutical soft-tissue changes in humans," European Radiology, vol. 11, no. 5, pp. 828833, 2001.

[16] P. A. Hein, C. J. Eskey, J. F. Dunn, and E. B. Hug, “Diffusionweighted imaging in the follow-up of treated high-grade 
gliomas: tumor recurrence versus radiation injury," American Journal of Neuroradiology, vol. 25, no. 2, pp. 201-209, 2004.

[17] M. C. DeLano, T. G. Cooper, J. E. Siebert, M. J. Potchen, and K. Kuppusamy, "High-b-value diffusion-weighted MR imaging of adult brain: image contrast and apparent diffusion coefficient map features," American Journal of Neuroradiology, vol. 21, no. 10, pp. 1830-1836, 2000.

[18] S. E. Maier, P. Bogner, G. Bajzik et al., "Normal brain and brain tumor: multicomponent apparent diffusion coefficient line scan imaging," Radiology, vol. 219, no. 3, pp. 842-849, 2001.

[19] J. M. Provenzale, S. T. Engelter, J. R. Petrella, J. S. Smith, and J. R. MacFall, "Use of MR exponential diffusion-weighted images to eradicate T2 'shine-through' effect," American Journal of Roentgenology, vol. 172, no. 2, pp. 537-539, 1999.

[20] W. Matzek, C. Czerny, C. Krestan et al., "Non-invasive therapy monitoring with diffusion weighted imaging: evaluation of effect of radiochemotherapy in squamous cell carcinoma of the oropharynx," in Proceedings of the 16th International Congress of Head \& Neck Radiology, Frankfurt, Germany, September 2003.

[21] M. Maeda and S. E. Maier, "Usefulness of diffusion-weighted imaging and the apparent diffusion coefficient in the assessment of head and neck tumors," Journal of Neuroradiology, vol. 35, no. 2, pp. 71-78, 2008.

[22] H. C. Thoeny, F. De Keyzer, and A. D. King, "Diffusion-weighted MR imaging in the head and neck," Radiology, vol. 263, no. 1, pp. 19-32, 2012.

[23] V. Vandecaveye, F. De Keyzer, P. Dirix, M. Lambrecht, S. Nuyts, and R. Hermans, "Applications of diffusion-weighted magnetic resonance imaging in head and neck squamous cell carcinoma," Neuroradiology, vol. 52, no. 9, pp. 773-784, 2010.

[24] J. P. Martínez Barbero, I. Rodríquez Jiménez, T. Martin Noguerol, and A. Luna Alcalá, "Utility of MRI diffusion techniques in the evaluation of tumors of the head and neck," Cancers, vol. 5, no. 3, pp. 875-889, 2013. 


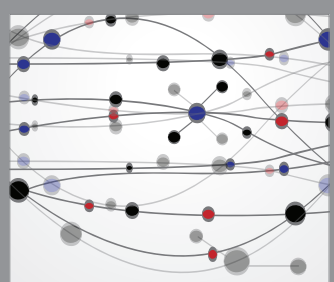

The Scientific World Journal
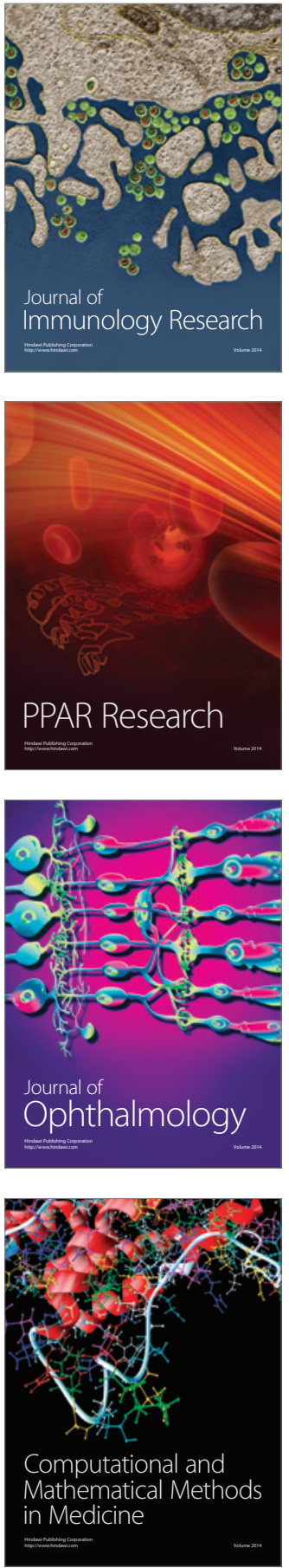

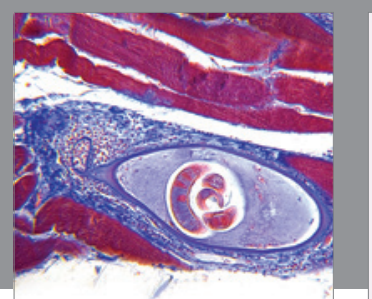

Gastroenterology Research and Practice

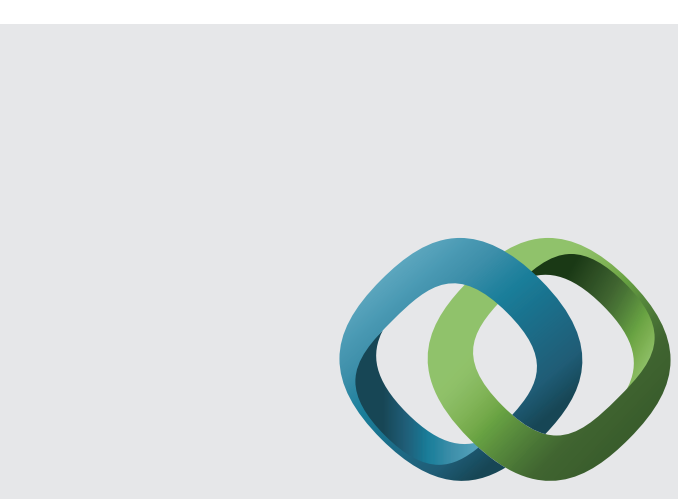

\section{Hindawi}

Submit your manuscripts at

http://www.hindawi.com
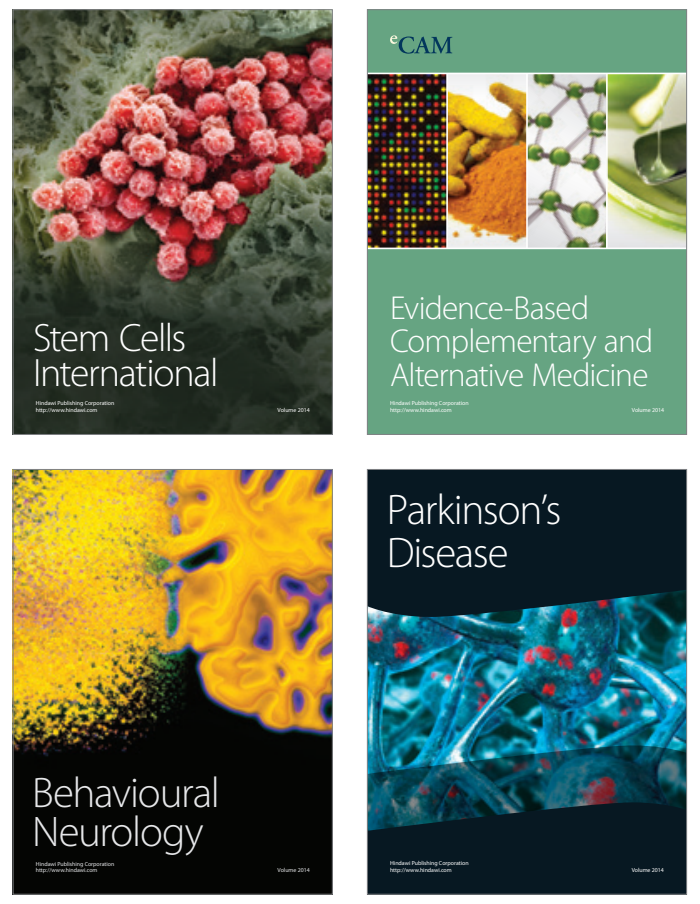
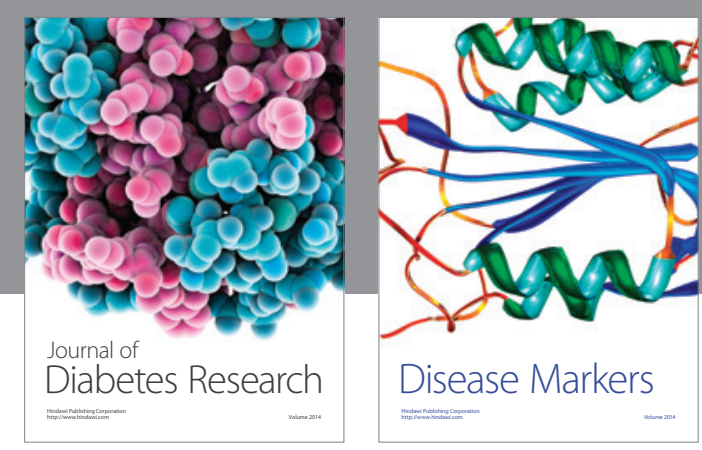

Disease Markers
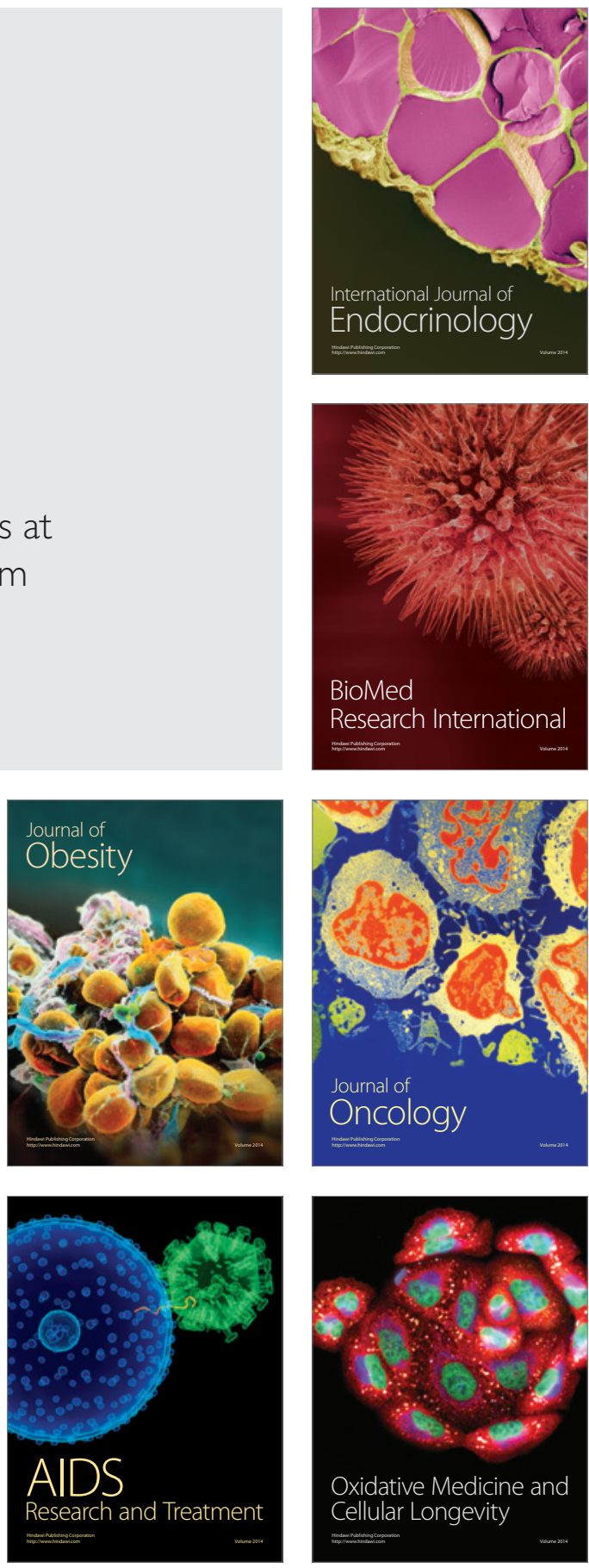